\title{
Metodologias Ativas: processo investigativo pela produção de vídeos
}

\section{Metodologías activas: proceso investigativo por la producción de vídeos}

\author{
Patrícia de Vargas Costa (patriciaulbra@hotmail.com) \\ Progra ma de Pós-Graduação em Ensino de Ciências Exatas - Universidade Federal do Rio Grande, \\ Campus Santo Antônio da Patrulha
}

Resumo: O presente trabalho tem por objetivo relatar uma experiência com metodologias ativas, no processo investigativo de produções de vídeos com es tudantes do $2^{\circ}$ ano da Escola Estadual de Ensino Médio "9 de Maio", do município de Imbé/RS. Os resultados evidenciaram que promover práticas associadas às metodologias ativas e ao uso das tecnologias digitais possibilitam um ensino colaborativo, dinâmico e criativo, o qual o estudante é protagonista de sua aprendizagem. Conclui-se que desenvolver práticas contex tualizadas e conexas à realidade do estudante potencializa a alfabetização científica.

Palavras-chave: Metodologias ativas; Projeto pedagógico; Produção de vídeos.

Resúmen: El presente trabajo tiene por objetivo relatar una experiência con metodologías activas, en el proceso investigativo de las producciones de vídeos con estudiantes de lo $2^{\circ}$ año de la Escuela Estadual del Enseñanza Media "9 de Maio", del ciudad del Imbé/RS. Los resultados han evidenciado que promover prácticas as ociadas a las metodologías activas y el uso de las tecnologías digitales posibilita una enseñanza colaborativa, dinamica y creativa, en lo cual el estudiante es el protagonista de su aprendizaje. Se concluye que desarrollar prácticas contextualizadas y conexas a la realidad del estudiante potencia la alfabetización científica.

Palabras clave: Metodologías activas; Proyecto pedagógico; Producción de vídeos.

\section{INTRODUÇÃO}

No âmbito da educação, as constantes transformações por que tem passado a sociedade ao longo do tempo vêm causando influências significativas. E o docente contemporâneo, diante dessa constatação, depara-se com diversos desafios na sua atuação, metodologia pedagógica e nas novas formas de aprendizagem.

Para que o docente possa acompanhar essa evolução, terá de revolucionar suas práticas, estimulando os estudantes na construção e produção do conhecimento, proporcionando-lhes um ambiente que favoreça a interpretações próprias, com 
autonomia para recriar, ampliando o que já conhecem. Para estimular essas competências é importante que o docente desenvolva práticas investigativas em sala de aula, como as metodologias ativas. Segundo Moran (2015), metodologias ativas são:

Pontos de partida para avançar processos mais a vançados de reflexão, de interação cognitiva, de generalização, de reelaboração de novas prática s. As metodologias a tivas seriam capazes de propiciar u m a profunda men to de competências e habilidades que colaborem para a construção do conhecimento do aluno (MORAN, 2015,p. 2).

A partir desse conceito, compreende-se que metodologias ativas auxiliam no processo de mediação entre docentes e estudantes durante as atividades pedagógicas de iniciação científica, potencializando assim uma aprendizagem significativa.

Diante dessa perspectiva, o processo investigativo com metodologias ativas foi desenvolvido numa turma do segundo ano da Escola Estadual de Ensino Médio "9 de Maio" do município de Imbé/RS, através de um projeto pedagógico com a temática Preservação do Meio Ambiente. Esta experiência foi realizada no Ensino Médio para atender a pesquisa acadêmica do curso de Pós-Graduação" sobre "O vídeo em sala de aula: estímulos audiovisuais como apoio ao ensino-aprendizagem".

Na execução da atividade foi proposto à turma que eles pudessem "assumir o papel protagonista, participando, criando, experimentando e refletindo sobre o aprendizado" (MORAN, 2018, p. 4). Essa postura teve como objetivo aproximá-los de um processo de aprendizagem mediado pelas metodologias ativas, ou seja, um en sino que centrado no aluno. Por esse viés emergiu o movimento ciência e tecnologia para uma possível alf abetização científica.

O projeto articulou o ensino interdisciplinar entre os componentes de Biologia, Artes, Língua Inglesa e Portuguesa, numa aprendizagem baseada na resolução de problema que, conforme Pozzo (1998, p. 15), consiste em "uma situação que um indivíduo ou um grupo quer ou precisa resolver e para a qual não dispõe de um caminho rápido e direto que o leve à solução".

A esse respeito Moran (2017) esclarece que:

$\mathrm{Na}$ a prendizagem por projetos, os a lunos se envolvem com tarefas e desafio s para resolver um problema ou desenvolverum projeto que também tenha ligação com sua vida fora da sala de aula. [...] Por meio de projetos, são

\footnotetext{
${ }^{1}$ Especia lização em Mídias na Educação - Ciclo Avançado pela UFRGS (2018).
} 
Edição Especial: XVI Encontro sobre Investigação na Escola - EIE

ISSN: 2595-4520 Vol. 4, n. 2. 2021

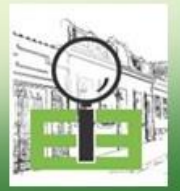

trabalhadas também suas habilidades de pensamento crítico, cria tiv o, e a percepção de que existem várias maneiras para a rea lização de u ma tarefa, a spectos esses tidos como competências necessá rias para o século XXI (MORAN, 2017, p. 75).

Ao propor esse movimento interdisciplinar, os docentes e estudantes envolvidos apresentaram a situação problema sobre "o impacto ambiental do Litoral Norte". A turma, juntamente com a pesquisadora, buscou informações sobre a temática para trazer as soluções para aquela situação problema. Para isso os estudantes utilizaram as mídias digitais como instrumento para demonstrar o seu desenvolvimento pedagógico e produziram vídeos como produto final.

O objetivo deste trabalho foi proporcionar um momento de discussão e produção mediado pelas potencialidades das metodologias ativas frente às questões ambientais no século XXI, a partir da produção de vídeos com um grupo de estudantes do Ensino Médio.

Para consolidar esta experiência, na figura abaixo apresenta-se um dos vídeos produzidos pela turma.

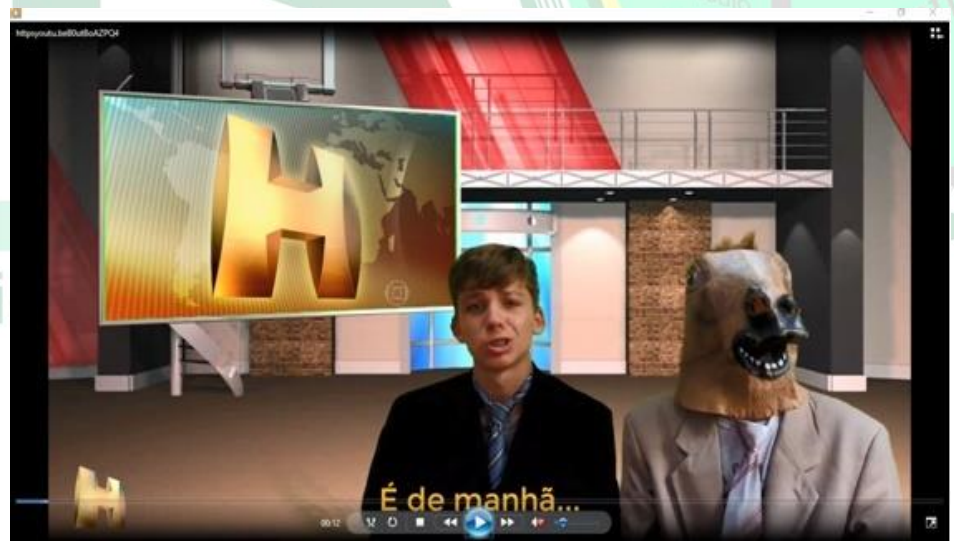

Figura 1: Preservação do Meio Ambiente

Fonte: https://www.youtube.com/watch?v=B0utBoAZPQ4 (2018)

\section{CONTEXTO E DETALHAMENTO DAS ATIVIDADES}

Posterior à escolha da temática "Preservação do Meio Ambiente", a turma reuniuse em pequenos grupos para executarem suas pesquisas e, sequencialmente, com assentimento da pesquisadora, elaboraram um vídeo informativo.

Os estudantes realizaram as pesquisas com a comunidade escolar e nos bairros mais próximos da cidade. Eles apontaram os principais agravos da sociedade perante o 
Edição Especial: XVI Encontro sobre Investigação na Escola - EIE

ISSN: $2595-4520$

Vol. 4, n. 2. 2021

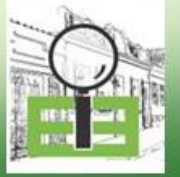

meio ambiente, como por exemplo, o descarte de lixo, reciclagem de materiais, poluição das águas e irresponsabilidade social. Estratégias foram elaboradas na tentativa de resolver o problema da temática e, ao mesmo tempo demonstrar à comunidade que é necessário cuidar da natureza.

Traçadas as estratégias, os estudantes trouxeram aos docentes e à pesquisadora, seus apontamentos e ideias de como poderiam trabalhar as questões ambientais junto à população. Os envolvidos fizeram uma de roda de conversa para debates, reflex ões e sugestões. Ao término, os estudantes partiram para a fase das dramatizações relativas ao tema em discussão. Para essa prática, elaboraram um vídeo informativo sobre preservação ambiental.

A produção do vídeo foi praticada por etapas, visto que necessitou dias de gravações devido aos diversos cenários. No primeiro momento (figura 2), os estudantes reuniram-se na residência de um dos integrantes com o roteiro pronto. Organizaram uma das dependências da casa, prepararam o cenário e deram início às gravações.

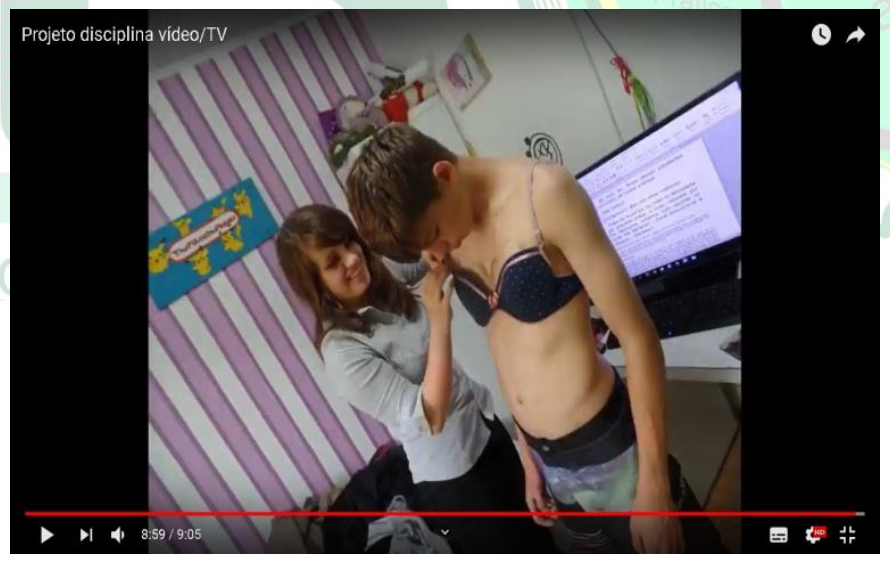

Figura 2: Residência do estudante Fonte: Costa, 2018

Num segundo momento, as gravações foram produzidas no lago "Braço Morto" (figura 3), um dos pontos turísticos da cidade de Imbé. Os estudantes, no decorrer das cenas, transmitiram conhecimentos sobre o tema.

Recebido em: 30 Aceito em: 19/1

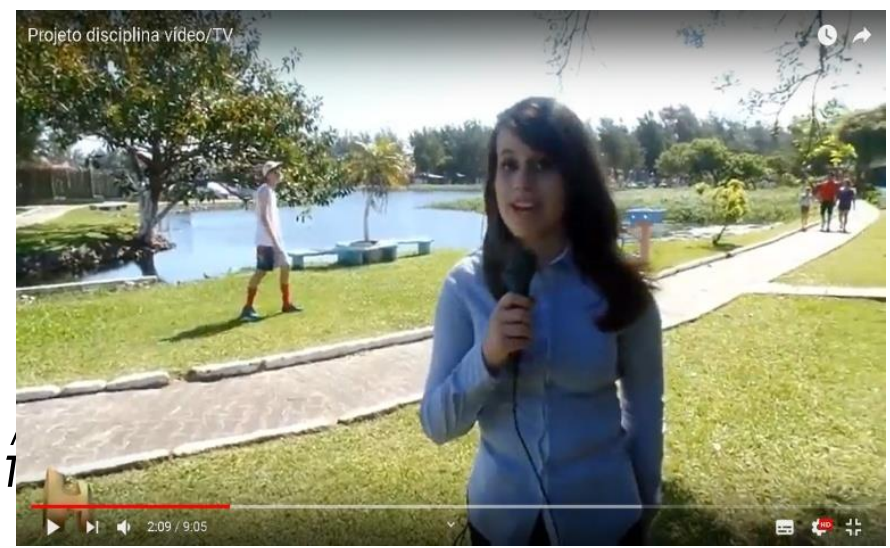


Dando continuidade ao vídeo, as gravações foram realizadas nas esquinas da Rua Frederico Westphalen e Av. Paraguassú, bem como da Rua Frederico Westphalen e Rua Sobradinho (figura 4). Nas cenas os estudantes desempenharam diálogos e atitudes cotidianas de poluições produzidas pela população da cidade de Imbé.
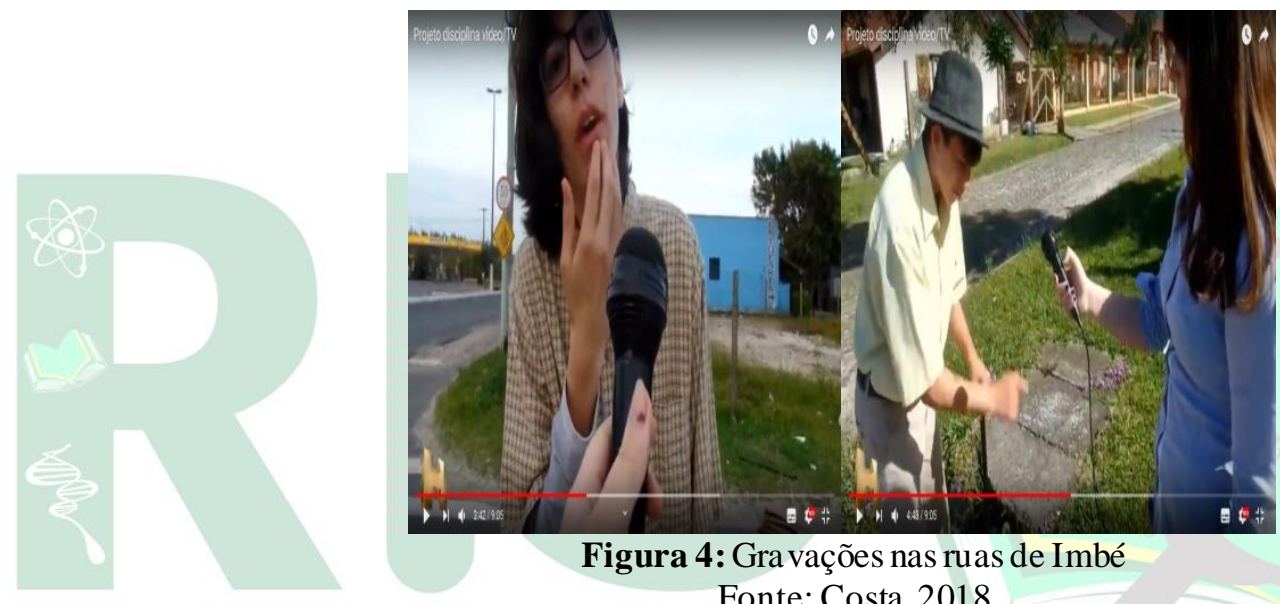

Figura 4: Gra vações nas ruas de Imbé Fonte: Costa, 2018

Para finalizar o vídeo, os estudantes gravaram algumas cenas e mensagens com o intuito de promover a conscientização da população sobre a importância da preservação do meio ambiente e do meio social em que se vive.

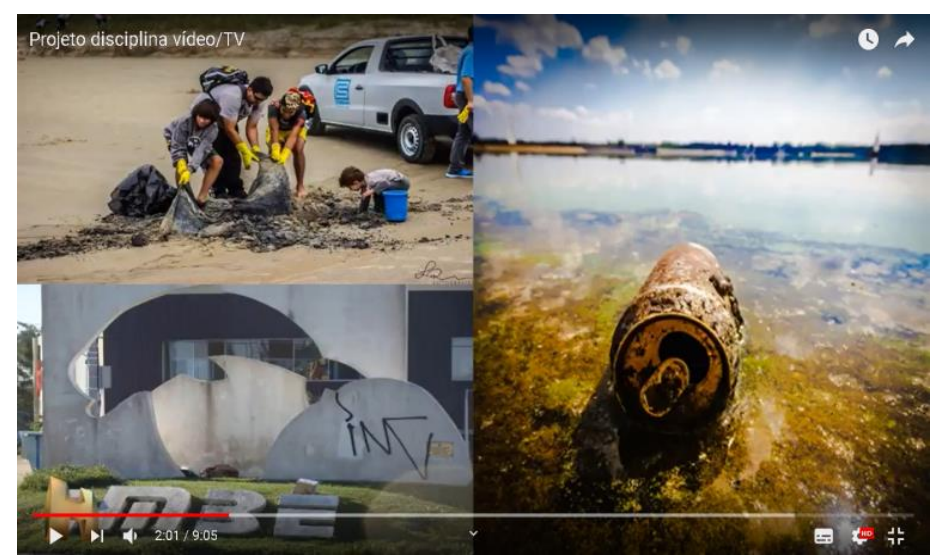

Figura 6: Con scientização à população

Fonte: Costa, 2018

No término das gravações, os estudantes reuniram as cenas para a montagem do vídeo, elaborando legendas e figuras para a construção da mídia. 


\title{
3. ANÁLISE E DISCUSSÃO DO RELATO
}

O projeto desenvolvido pelos alunos do $2^{\circ}$ ano do Ensino Médio foi significativo, tanto para os docentes e pesquisadora, quanto para os estudantes, visto que oportunizou uma aprendizagem mais dinâmica, criativa e ativa. De acordo com Marinho (2013):

\begin{abstract}
Um a luno motivado intrinsecamente envolve-se nas a tividades ou tarefas pelo qual elas são compreendendo-as como a gradáveis e proporcionando-lhe sa tisfação. Essa satisfação funciona como recompensa interna e não está dependente de objetos externos. Um aluno intrin secamente motivado ef et ua as atividades porque tem prazer na execução dessas mesmas tarefas (MARINHO, 2013, p.50).
\end{abstract}

Neste processo o professor teve o papel fundamental. Para tanto, foi necessário personificar suas aulas em conformidade com o contexto social e ainda, ser um motivador da aprendizagem na relação com seus estudantes.

Inicialmente, na execução do projeto, percebeu-se o entrosamento dos estudantes com o tema e o quanto expressavam e dominavam bem o conteúdo. Durante as observações os estudantes desenvolveram autonomia, apontaram o problema, ao participarem das atividades, apresentaram soluções para o problema e criaram estratégias de preservação do meio ambiente.

Realizar a atividade potencializou o diálogo entre professores e alunos, promovendo um ensino de reciprocidade, uma mudança cultural e comportamental de ambas as partes. A esse respeito Moran (2017) ressalta que:

\begin{abstract}
A personalização, do ponto de vista do educador e da escola, é o movimento de ir ao encontro das necessidades e interesses dos estudantes e de ajudá-los a desenvolver todo o seu potencial, a motivá-los, a en gajá-los em projetos significativos, na construção de conhecimentos mais profundos e no desenvolvimento de competências mais a mplas (MORAN, 2017, p. 81).
\end{abstract}

Na continuidade, foi proporcionada à turma uma roda de conversas para que os estudantes pudessem apresentar o material coletado nas pesquisas que realizaram com a comunidade escolar e nos bairros próximos. . Nesse momento trouxeram ainda possíveis soluções para o problema da temática. A roda de conversas possibilitou a troca de experiências pessoais e culturais na turma, pois ao interagir com outros sujeitos em atividades práticas, essa ação contribuiu para o aperfeiçoamento da aprendizagem no

Recebido em: $30 / 04 / 2020$

Aceito em: 19/11/2020 
Edição Especial: XVI Encontro sobre Investigação na Escola - EIE

ISSN: 2595-4520 Vol. 4, n. 2. 2021

plural, a qual é constituída por saberes de diversos contextos. Relacionando a experiência aqui compartilhada, sublinha-se a argumentação de Vygotsky (1984, p. 70):

“[...] a aula é uma celebração, um banquete, uma confraternização amorosa, uma comunhão de inteligência; quando o educador é consciente da interação social que gerou a cultura humana".

No último momento, quando os estudantes produziram o vídeo, percebe-se o entrosamento e o aprender coletivo. O que condiz com o pensamento de Vygotsky (1984) na citação acima. Nas gravações das cenas do vídeo informativo foi observado o domínio do conteúdo da temática proposta no projeto elaborado pelos estudantes, bem como a interação social e a combinação de metodologias ativas com as tecnologias digitais. Santos (2015, p.94) afirma que trabalhar com tecnologias digitais na edu cação é imprescindível, pois "solicita constantemente a imaginação e reinveste a afetividade com um papel de mediação primordial do mundo, ao passo que linguagem escrita trabalha mais o rigor, a organização, a abstração e a análise lógica".

$\mathrm{O}$ uso de tecnologias digitais no ambiente escolar, quando utilizadas de maneira planejada apresenta um potencial pedagógico que possibilita novas formas de ensinar e aprender coletiva e continuamente. Nesta interação, docentes e os discentes compartilham saberes, ressignificando-os e celebrando-os diariamente através das palavras faladas e da dinamização da sala de aula.

\section{CONSIDERAÇÕES FINAIS}

Desenvolver um ensino com metodologias ativas direcionadas ao movimento ciência, tecnologia, sociedade e ambiente (CTSA), em que o desenvolvimento das atividades curriculares é contextualizado e ofertado por temáticas, possibilita uma aprendizagem colaborativa, tornando o estudante mais atento e ativo em sua aprendizagem. Proporciona ainda uma pedagogia de projetos que atue com temáticas próximas à realidade cultural do estudante. Referente a essa implementação de temáticas ao currículo, Auler (2003) salienta:

A ca minhada quan to à ela boração e a valiação da implementação de temáticas encontra-se numa fase bastante preliminar. Contudo, há indicativos de que a opção por esta configuração curricular gera um maior engajamen to do a lun o

Recebido em: 30 /04/ 2020

Aceito em: 19/11/2020 
Edição Especial: XVI Encontro sobre Investigação na Escola - EIE

ISSN: 2595- $4520 \quad$ Vol. 4, n. 2. 2021

em todo o processo. Em outras palavras, favorecendo uma maior ressonância entre o "mundo da escola" e o "mundo da vida", a a tribuição de signif ica do a o que se faz na escola, por parte do aluno, pode constituir-se numa dimensão que potencializa a a prendizagem (AULER, 2003,p. 80).

Projetos pedagógicos propostos como neste relato de experiência, aplicados com a intenção de tentar resolucionar algum problema próximo a realidades em que os estudantes interagem, podem promover uma leitura de mundo (Freire, 1987). A potencialização da aprendizagem efetiva-se por um currículo promovido a partir da realidade do discente. Com isso é possível fazer uma leitura de conteúdos de ciência, refletindo sobre o mundo em que vivemos e as implicações desse viver, na tomada de decisões, no exercício da cidadania.

\section{REFERÊNCIAS}

AULER, D. Alfabetização Científico-Tecnológica: Um Novo "Paradigma"? Ensaio. Belo Horizonte: v. 5, n.1, p.68-83, 2003.

COSTA, P. V. O vídeo em sala de aula: estímulos audiovisuais como apoio ao ensinoaprendizagem. 2018.43 f. Monografia de Pós-Graduação Mídias na Educação. Universidade Federal do Rio Grande do Sul, Porto Alegre, 2018.

FREIRE, P. Pedagogia do Oprimido. 17 ed. Rio de Janeiro: Paz e Terra, 1987.

MARINHO, J. (2013). A motivação intrínseca no 1. ${ }^{\circ}$ Ciclo do Ensino Básico:

Contributos do Projeto Curricular Integrado. Relatório mestrado apresentado na Universidade do Minho. [Em linha]. Disponível em

http://repositorium.sdum.uminho.pt/handle/1822/28698. Acesso em: 12/03/2020.

MORAN, J. et al. Educação 3.0: Novas Perspectivas para o ensino. 2017.

MORAN J. Metodologias Ativas para uma Educação Inovadora. Penso Editora Ltda. São Paulo. 2018.

POZZO, J. I. (org.) A Solução de problemas: aprender a resolver, resolver para aprender. Porto Alegre: Artmed, 1998.

Recebido em: 30 /04/ 2020

Aceito em: 19/11/2020 
Edição Especial: XVI Encontro sobre Investigação na Escola - EIE

SANTOS, M. P. Vídeo educativo como tecnologia audiovisual: antecedentes

históricos e implicações pedagógico-metodológicas. Revista Educação, Cultura e

Sociedade, v. 5, n. 1, p. 83-106, 2015.

VYGOTSKY, L.S. A formação social da mente. São Paulo: Martins Fontes, 1984. 